\title{
Particle Swarm Intelligence based allocation of FACTS controller for the increased load ability of Power system
}

\author{
Biplab Bhattacharyya ${ }^{1}$, S.K.Goswami ${ }^{2}$, Vikash Kumar Gupta ${ }^{3}$ \\ ${ }^{1}$ Dept. of EE, Indian School of Mines, Dhanbad, Jharkhand, India \\ ${ }^{2}$ Dept. of EE, Jadavpur University, Kolkata, India \\ ${ }^{3}$ Dept. of EE, Indian School of Mines, Dhanbad, Jharkhand, India
}

\begin{abstract}
This paper presents Particle Swarm Optimization (PSO) based approach for the allocation \& coordinated operation of multiple FACTS (Flexible AC Transmission System) devices for the economic operation as well as to increase power transfer capacity of an interconnected power system under different loading condition. The PSO based approach is applied on IEEE 30-bus system. The system is reactively loaded starting from base to $200 \%$ of base load. FACTS devices are installed in the different locations of the power system and system performance is noticed with and without FACTS devices. First, the locations, where the FACTS devices to be placed is determined by calculating active and reactive power flows in the lines. A Particle Swarm Optimization based algorithm is then applied to find the amount of magnitudes of the FACTS devices. This Particle Swarm Optimization based approach for the placement of FACTS devices Yields promising result both in terms of performance and economy which is clearly observed from the result obtained.
\end{abstract}

Keywords: FACTS Devices, Line Power Flow, Optimal Location of FACTS Devices, Particle Swarm Optimization.

\section{Introduction}

In recent years power demand has increased substantially while the expansion of power generation and transmission has been limited due to limited resources and environmental restrictions. As a consequence some transmission lines are heavily loaded and system stability becomes a power transfer limiting factor. Flexible AC transmission system (FACTS) controllers are mainly used for solving various power system steady state control problems. However recent studies reveal that FACTS controllers could be employed to enhance power system stability in addition to their main function of power flow control. It is known that the power flow through an ac transmission line is a function of line impedance, the magnitude and the phase angle between the sending and the receiving end voltages. By proper coordination of FACTS devices in the power system network, both the active and reactive power flow in the lines can be controlled. Tighter control of power flow and the increased use of transmission capacity by FACTS devices are discussed in [1]. A scheme of power flow control in lines is discussed in [2]. The system load ability and loss minimization are used as an objective function. Use of static phase shifters and FACTS controllers to increase the power transfer capacity in the transmission line is described in [3]-[4]. A simple approach based on the optimal location of FACTS devices are discussed in [5]. Modeling and optimum location of variable FACTS devices are discussed in [6]-[7]. Power injection model of FACTS devices and Optimal Power Flow (OPF) model is discussed in [8]-[9] which present a novel power flow control approach to enable the working of different FACTS devices. Assessment and Impact of FACTS devices on power networks have been discussed in [10] through the concept of steady state security regions. The placement of different FACTS devices in a power system using Genetic Algorithm is discussed [11]. The system load ability is carried out to measure power

Received: July $11^{\text {th }}, 2012$. Accepted: December $7^{\text {th }}, 2012$ 
system performance. In [12] authors have discussed about the most important feature of the TCSC i.e. its variable degree of compensation that can be used in damping out low-frequency oscillations, controlling the power flow, etc. In [13] an adaptive stabilizer design for SVC control in power systems for either voltage regulation or controlling dynamic and transient performance under abnormal condition is discussed. Steady state firing angle model of SVC and TCSC for power flow solution were developed and discussed in [14]. Use of Thyristor Controlled Series Capacitor (TCSC), Unified Power Flow Controller (UPFC), Thyristor Controlled Voltage regulator (TCVR), and Static Var Compensator (SVC) were studied in [15] for increased power flow.

The objective of this present work is the optimal allocation of FACTS devices in the transmission network so the transmission loss becomes minimized and also for the simultaneous increase of power transfer capacity of the transmission network that ultimately yields minimum operating cost under various loading conditions. Minimization of transmission loss is a problem of reactive power optimization and can be done by controlling reactive generations of the generators, controlling transformer tap positions and adding shunt capacitors in the weak buses [16] but the active power flow pattern can not be controlled. Power flow control with different FACTS devices were discussed in [17]. In the proposed work, first the locations of the FACTS devices are identified by calculating different line flows. TCSC's are placed in lines where reactive power flows are very high and the SVC's are connected at the receiving end buses of the other lines carrying significant amount of reactive power.

\section{FACTS Devices}

\section{Modeling of FACTS Devices}

For the steady state analysis it is necessary to model the FACTS devices mathematically. Thyristor controlled switched capacitors (TCSC) and Static VAr Compensators (SVC) are used as FACTS devices in the transmission network in this approach.

\section{TCSC}

TCSC acts as either inductive or capacitive compensator by changing the line reactance. The maximum value of the capacitance is fixed at $-0.8 \mathrm{X}_{\mathrm{r}}$ and $0.2 \mathrm{X}_{\mathrm{r}}$ is the maximum value of the inductance, where $\mathrm{X}_{\mathrm{r}}$ is the line reactance. When a TCSC is connected to a particular line, its admittance can be written as

$$
\mathrm{G}_{\mathrm{TCSC}}+\mathrm{jB}_{\mathrm{TCSC}}=\frac{1}{\mathrm{R}+\mathrm{j}(\mathrm{X}+\mathrm{Xtcsc})}
$$

where $\mathrm{R}$ and $\mathrm{X}$ are the resistance and reactance of the line without TCSC.

TCSC allows faster changes of transmission line impedance. Figure 1 shows the mathematical model of TCSC connected with transmission lines.

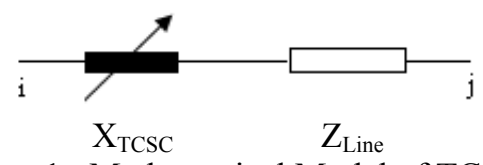

Figure 1. Mathematical Model of TCSC.

$$
\begin{aligned}
& Z_{\text {Line }}=R+j X_{L} \\
& X_{\mathrm{ij}}=X_{L}+X_{\text {TCSC }} \\
& X_{\text {TCSC }}=r_{\text {TCSC }} \times X_{L} \\
& \text { Where } \\
& X_{\text {Line }}=\text { Reactance of the transmission line. }
\end{aligned}
$$


$\mathrm{X}_{\mathrm{TCSC}}=$ Reactance of TCSC.

$\mathrm{r}_{\mathrm{TCSC}}=$ Coefficient which represents the compensation degree of TCSC.

$\underline{\mathrm{SVC}}$

SVC can be considered as to generate or absorb controllable reactive power by synchronously switching capacitor and reactor banks "in" and "out" of the network. The main function of SVC to absorb reactive power from the bus or to inject reactive power to the bus where it is installed. The SVC's effective reactance $\mathrm{X}_{\mathrm{SVC}}$ is determined by parallel combination of $\mathrm{X}_{\mathrm{C}}$ \& $\mathrm{X}_{\mathrm{L}}$ and is given by

$$
\mathrm{X}_{\mathrm{SVC}}=\frac{\pi \mathrm{X}_{\mathrm{C}} \mathrm{X}_{\mathrm{L}}}{\mathrm{X}_{\mathrm{C}}[2(\pi-\alpha)+2 \sin \alpha]-\pi \mathrm{X}_{\mathrm{L}}}
$$

where $\alpha$ is the firing angle.

The SVC model is shown in figure 2.

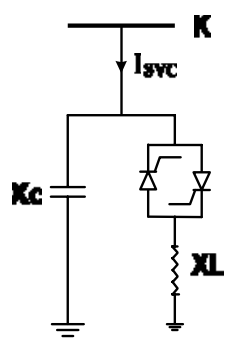

Figure 2. SVC firing angle model.

FACTS Devices cost Functions

TCSC:

$\mathrm{C}_{\mathrm{TCSC}}=0.0015(\mathrm{OR})^{2}-0.7130(\mathrm{OR})+127.38(\mathrm{US} \$ / \mathrm{kVar})$

SVC:

$\mathrm{C}_{\mathrm{SVC}}=0.0003(\mathrm{OR})^{2}-0.2691(\mathrm{OR})+188.22(\mathrm{US} \$ \mathrm{kVar})$

Here, $(\mathrm{OR})$ is the operating range of the FACTS Devices.

\section{Optimal Placement of FACTS devices}

Having made the decision to install a FACTS device in the system, there are three main issues that are to be considered: types of device, its capacity and location. The decision where they are to be placed is largely dependent on the desired effect and the characteristics of the specific system. SVCs are mostly suitable when reactive power flow or voltage support is necessary. TCSC devices are not suitable in lines with high Reactive Power flow. Also the costs of the devices play an important role for the choice of a FACTS device. There are two distinct means of placing a FACTS device in the system for the purpose of increasing the system's ability to transmit power, thereby allowing for the use of more economic generating units. That is why FACTS devices are placed at the more heavily loaded lines to limit the power flow in that line. This causes more power to be sent through the remaining portions of the system while protecting the line with the device for being overloaded. This method which sites the devices in the heavily loaded line is the most effective. If reactive power flow is a significant portion of the total flow on the limiting transmission line, either a TCSC device in the line or a SVC device located at the end of the line that receives the reactive power, may be used to reduce the reactive power flow, thereby increasing the active power flow capacity. 


\section{The Proposed Approach}

Here the main objective is to minimize the total operational cost under different loading situation by incorporating FACTS devices at suitable locations of the transmission network. Inclusion of FACTS controllers also increase the system cost. So, optimal placements of FACTS devices are required such that the gain obtained by reducing the transmission loss is significant even after the placement of costly FACTS devices. Installation costs of various FACTS devices and the cost of system operation, namely, energy loss cost are combined to form the objective function to be minimized. Besides FACTS devices, transmission loss can be minimized by optimization of reactive power, which is possible by controlling reactive generations of the generator's, controlling transformer tap settings, and by the addition of shunt capacitors at weak buses. But with FACTS devices both the active and reactive power flow pattern can be changed and results significant changes in the system performance. The optimal allocation of FACTS Devices can be formulated as:

$$
\mathrm{C}_{\mathrm{TOTAL}}=\mathrm{C}_{1}(\mathrm{E})+\mathrm{C}_{2}(\mathrm{~F})
$$

where $C_{1}(E)$ is the cost due to energy loss and $C_{2}(F)$ is the total investment cost of the FACTS Devices.

Subject to the nodal active and reactive power balance

$$
\begin{aligned}
& P_{n i}^{\min } \leq P_{n i} \leq P_{n i}^{\max } \\
& Q_{n i}^{\min } \leq Q_{n i} \leq Q_{n i}^{\max }
\end{aligned}
$$

voltage magnitude constraints: $V_{i}^{\min } \leq V_{i} \leq V_{i}^{\max }$

and the existing nodal reactive capacity constraints:

$$
Q_{g i}^{\min } \leq Q_{g i} \leq Q_{g i}^{\max }
$$

Superscripts min, max are the minimum and maximum limits of the variables.

The power flow equations between the nodes i-j after incorporating FACTS devices would appear as

\section{TCSC:}

$$
\begin{aligned}
& \mathrm{P}_{\mathrm{Gi}}-\mathrm{P}_{\mathrm{Di}}+\mathrm{P}_{\mathrm{i}}-\sum_{j=1}^{N-1} V_{i} V_{j}\left(G_{i j} \cos \theta_{i j}+B_{i j} \sin \theta_{i j}\right)=0 \\
& \mathrm{Q}_{\mathrm{Gi}}-\mathrm{Q}_{\mathrm{Di}}+\mathrm{Q}_{\mathrm{i}(\mathrm{inj})}-\sum_{\mathrm{j}=1}^{\mathrm{N}-1} \mathrm{~V}_{\mathrm{i}} \mathrm{V}_{\mathrm{j}}\left(\mathrm{G}_{\mathrm{ij}} \sin \theta_{\mathrm{ij}}-\mathrm{B}_{\mathrm{ij}} \cos \theta_{\mathrm{ij}}\right)=0 \\
& \mathrm{P}_{\mathrm{Gj}}-\mathrm{P}_{\mathrm{Dj}}+\mathrm{P}_{\mathrm{i}}-\sum_{j=1}^{N-1} V_{j} V_{j}\left(G_{j j} \cos \theta_{j j}+B_{j j} \sin \theta_{j j}\right)=0 \\
& Q_{G j}-Q_{D j}+Q_{j(i n j)}-\sum_{j=1}^{N-1} V_{j} V_{j}\left(G_{j j} \sin \theta_{j j}-B_{j j} \cos \theta_{j j}\right)=0
\end{aligned}
$$

SVC:

$$
\mathrm{Q}_{\mathrm{Gi}}-\mathrm{Q}_{\mathrm{Di}}+\mathrm{Q}_{\mathrm{iL}(\mathrm{inj})}-\sum_{\mathrm{j}=1}^{\mathrm{N}-1} \mathrm{~V}_{\mathrm{i}} \mathrm{V}_{\mathrm{j}}\left(\mathrm{G}_{\mathrm{ij}} \sin \theta_{\mathrm{ij}}-\mathrm{B}_{\mathrm{ij}} \cos \theta_{\mathrm{ij}}\right)=0
$$


$\mathrm{P}_{\mathrm{i}}$ and $\mathrm{Q}_{\mathrm{i}(\mathrm{inj})}$ are the real and reactive power flow change takes place at the nodes due to TCSC connected to a particular line between the nodes $\mathrm{i} \& \mathrm{j}$. $\mathrm{Q}_{\mathrm{iL}(\mathrm{inj})}$ is the reactive power injection due to SVC. These changes in the power flow equations are taken into consideration by appropriately modifying the admittance bus matrix for execution of load flow in evaluating the objective function for each individual population of generation both in the cases of Genetic Algorithm and Particle Swarm Optimization based approaches.

In this approach, first the locations of FACTS devices are defined by calculating the power flow in the transmission lines. Then TCSC positions are selected by choosing the lines carrying largest reactive power. Lines $25,41,28 \& 5$ are found as the lines for TCSC placement and simultaneously series reactance of these lines are controlled. $21^{\text {st }}, 7^{\text {th }}, 17^{\text {th }} \& 15^{\text {th }}$ buses are found as the buses where suitable reactive injection by SVC could improve the system performance.

PSO approach in brief:

The formulae on which PSO works is given as

$$
v_{i}^{k+1}=\omega_{i} v_{i}^{k}+C_{1} \text { rand } \times\left(P_{\text {best }_{i}}-S_{i}^{k}\right)+C_{2} \text { rand } \times\left(g_{\text {best }}-S_{i}^{k}\right)
$$

Where,

$$
v_{i}^{k} \rightarrow
$$

current velocity of agent $i$ at iteration $k$,

$$
\omega=\omega_{\max }-\frac{\omega_{\max }-\omega_{\min }}{\text { iter }_{\max }} \times \text { iter } \rightarrow \text { is the modified velocity of the ith agent }
$$

rand $\rightarrow$ is the random number between 0 and 1 ,

$S_{i}^{k} \rightarrow$ current position of agent $i$ at iteration $k$,

$\mathrm{C}_{\mathrm{i}} \rightarrow$ weight coefficient for each term,

$P_{\text {best }} \rightarrow P_{\text {best }}$ of agent $i$,

$g_{\text {best }} \rightarrow g_{\text {best }}$ of the group,

$\omega_{i} \rightarrow$ weight function for velocity of agent $i$.

Where $\omega$ is updated by the following equation at each iteration

$$
\omega=\omega_{\max }-\frac{\omega_{\text {max }}-\omega_{\min }}{\text { iter }_{\text {max }}} \times \text { iter }
$$

Here $\omega_{\max }=0.9, \omega_{\min }=0.4$, iter $_{\max }=500$ and iter $=$ current iteration, $\mathrm{C}_{1}$ and $\mathrm{C}_{2}$ are set to 2.0.

PSO is used after the solution obtained by the Fuzzy approach for optimal setting of transformer tap positions, Generator's reactive generations. Here the control variables are represented with in a string. Initially strings are generated randomly and each string may be a potential solution. In PSO, each potential solution, called particles is assigned a velocity. The particles of the population always adjust their velocity depending upon their position with respect to the position of the pbest (the particle having the best fitness in the current generation) and the gbest (the particle having the best fitness upto the present generation). While adjusting their velocities and positions, particles adjust their fitness value as well. The particle having the best fitness among all is selected as the pbest for the current generation, and if this pbest has better fitness than the gbest, it takes the position of the gbest as well. In PSO, therefore, the gbest particle always improves its position and finds the optimum solution and the rest of the population follows it. The string length depends upon the problem and the control variables within the string are shown in figure 3 . 
Biplab Bhattacharyya, et al.

\begin{tabular}{|c|c|c|c|c|c|c|c|c|c|c|c|c|c|c|c|c|}
\hline \multicolumn{4}{|c|}{ TCSC } & \multicolumn{4}{|c|}{ SVC } & \multicolumn{4}{|c|}{ Transformer Tap } & \multicolumn{5}{|c|}{$\begin{array}{c}\text { Reactive Generations of } \\
\text { Generators }\end{array}$} \\
\hline 1 & 2 & 3 & 4 & 1 & 2 & 3 & 4 & 1 & 2 & 3 & 4 & 1 & 2 & 3 & 4 & 5 \\
\hline
\end{tabular}

Figure 3. Strings Representing the Control Variables.

Figure 4. Shows flowchart of proposed power flow in PSO approach.

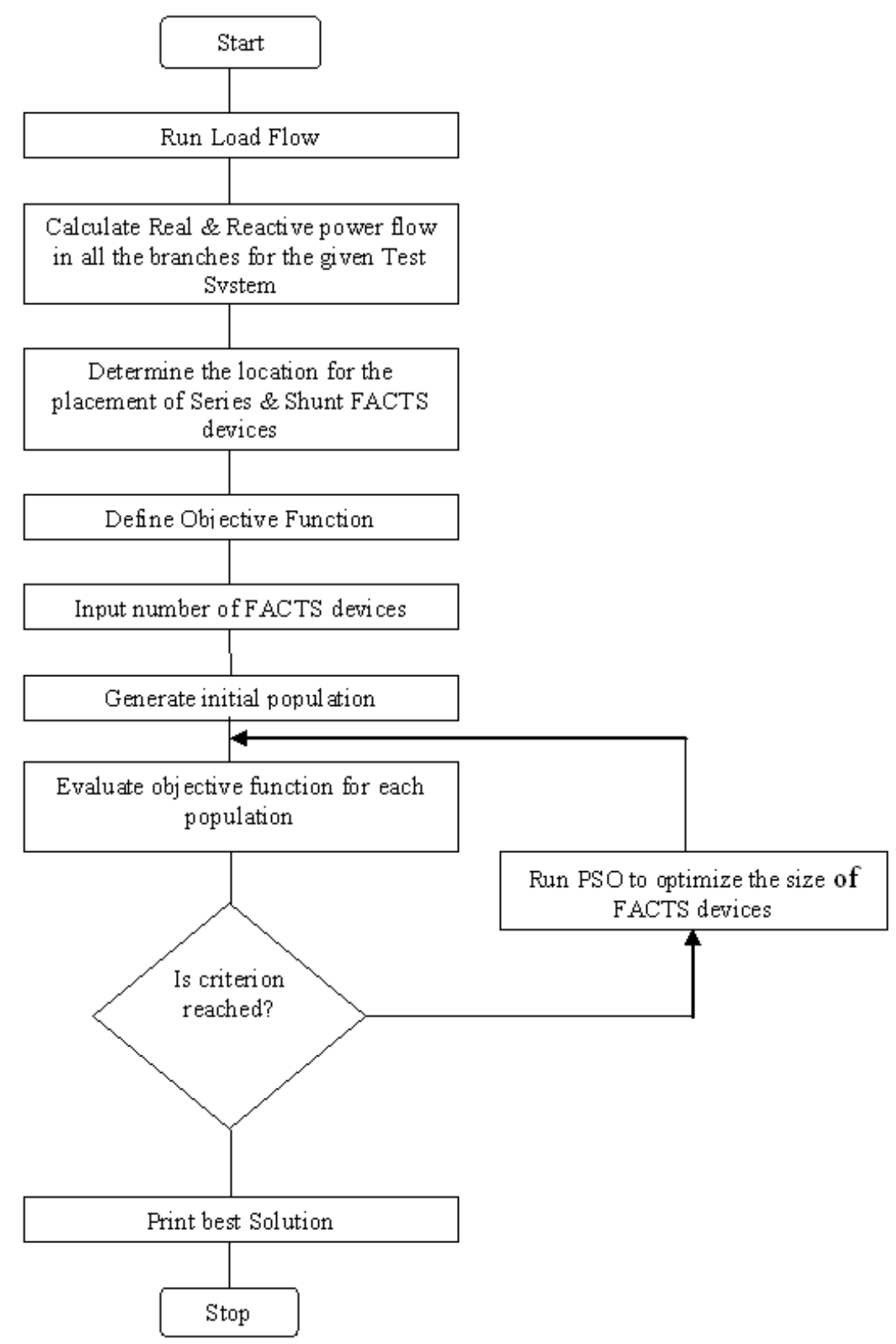

Figure 4. Flowchart of proposed power flow in PSO. 
Table 1. Reactive power flow without FACTS devices.

\begin{tabular}{|c|c|c|c|}
\hline Base & $\begin{array}{c}150 \% \text { Base } \\
\text { Reactive } \\
\text { Load }\end{array}$ & $\begin{array}{c}175 \% \text { Base } \\
\text { Reactive } \\
\text { Load }\end{array}$ & $\begin{array}{c}200 \% \text { Base } \\
\text { Reactive } \\
\text { Load }\end{array}$ \\
\hline 0.0150 & 0.0140 & 0.0133 & 0.0126 \\
-0.0033 & 0.0153 & 0.0248 & 0.0345 \\
-0.0582 & -0.0363 & -0.0250 & -0.0136 \\
-0.0277 & -0.0153 & -0.0090 & -0.0025 \\
0.0390 & 0.0387 & 0.0386 & 0.0384 \\
-0.0510 & -0.0312 & -0.0211 & -0.0107 \\
0.0241 & 0.0165 & 0.0126 & 0.0086 \\
0.0297 & 0.0696 & 0.0899 & 0.1105 \\
0.0731 & 0.0884 & 0.0958 & 0.1032 \\
0.0134 & -0.0703 & -0.1133 & -0.1572 \\
-0.1101 & -0.0751 & -0.0571 & -0.0386 \\
-0.0314 & -0.0028 & 0.0120 & 0.0270 \\
-0.2252 & -0.2746 & -0.2998 & -0.3254 \\
0.0315 & 0.178 & 0.1618 & 0.2064 \\
-0.0685 & -0.0341 & -0.0164 & 0.0016 \\
-0.3016 & -0.3874 & -0.4308 & -0.4747 \\
0.0198 & 0.0346 & 0.0421 & 0.0497 \\
0.0507 & 0.0930 & 0.1146 & 0.1365 \\
0.0168 & 0.0427 & 0.0559 & 0.0692 \\
0.0024 & 0.0089 & 0.0122 & 0.0155 \\
-0.0020 & 0.0145 & 0.0228 & 0.0313 \\
0.0091 & 0.0234 & 0.0307 & 0.0380 \\
-0.0005 & 0.0091 & 0.0139 & 0.0188 \\
-0.0346 & -0.0420 & -0.0457 & -0.0493 \\
0.0441 & 0.0553 & 0.0608 & 0.0664 \\
0.0608 & 0.0735 & 0.0798 & 0.0860 \\
0.0939 & 0.1430 & 0.1677 & 0.1925 \\
0.0419 & 0.0650 & 0.0766 & 0.0883 \\
-0.0205 & -0.0283 & -0.0323 & -0.0361 \\
0.0149 & 0.0360 & 0.0467 & 0.0576 \\
0.0204 & 0.0351 & 0.0425 & 0.0500 \\
-0.0016 & 0.0113 & 0.0178 & 0.0244 \\
-0.0073 & -0.0155 & -0.0195 & -0.0235 \\
0.0237 & 0.0355 & 0.0414 & 0.0474 \\
-0.0310 & -0.0510 & -0.0611 & -0.0712 \\
-0.0383 & -0.0027 & 0.0156 & 0.0345 \\
0.0166 & 0.0240 & 0.0277 & 0.0315 \\
0.0166 & 0.0237 & 0.0273 & 0.0309 \\
0.0060 & 0.0087 & 0.0101 & 0.0114 \\
0.0083 & 0.0306 & 0.0421 & 0.0539 \\
0.0421 & 0.0581 & 0.0665 & 0.0751 \\
\hline & & & \\
\hline
\end{tabular}

Table 2. Location of different FACTS devices in the transmission network.

\begin{tabular}{|c|c|}
\hline TCSC in lines & SVC in Buses \\
\hline $25,41,28,5$ & $21,7,17,15$ \\
\hline
\end{tabular}


Biplab Bhattacharyya, et al.

Table 3. Bus Voltage and Phase angle for $200 \%$ reactive loading.

\begin{tabular}{|c|c|c|c|c|}
\hline $\begin{array}{l}\text { Bus } \\
\text { No. }\end{array}$ & $\begin{array}{c}\text { Bus Voltage } \\
\text { Without } \\
\text { FACTS }\end{array}$ & $\begin{array}{c}\text { Bus Voltages } \\
\text { With FACTS } \\
\text { using PSO }\end{array}$ & $\begin{array}{c}\text { Bus angle } \\
\text { without } \\
\text { FACTS }\end{array}$ & $\begin{array}{c}\text { Bus angle } \\
\text { With FACTS } \\
\text { using PSO }\end{array}$ \\
\hline 1 & 1.0500 & 1.0500 & 0.0000 & 0 \\
\hline 2 & 1.0338 & 1.0338 & -0.0481 & -0.0483 \\
\hline 3 & 1.0284 & 1.0215 & -0.0813 & -0.0793 \\
\hline 4 & 1.0231 & 1.0149 & -0.0975 & -0.0951 \\
\hline 5 & 1.0058 & 1.0058 & -0.1579 & -0.1591 \\
\hline 6 & 1.0182 & 1.0100 & -0.1127 & -0.1112 \\
\hline 7 & 1.0014 & 0.9952 & -0.1391 & -0.1383 \\
\hline 8 & 1.0230 & 1.0230 & -0.1137 & -0.1146 \\
\hline 9 & 1.0302 & 1.0933 & -0.1415 & -0.1380 \\
\hline 10 & 1.0135 & 1.0801 & -0.1755 & -0.1694 \\
\hline 11 & 1.0913 & 1.0913 & -0.1083 & -0.1067 \\
\hline 12 & 1.0295 & 1.0674 & -0.1644 & -0.1511 \\
\hline 13 & 1.0883 & 1.0883 & -0.1432 & -0.1307 \\
\hline 14 & 1.0096 & 1.0558 & -0.1789 & -0.1658 \\
\hline 15 & 1.0036 & 1.0574 & -0.1795 & -0.1711 \\
\hline 16 & 1.0122 & 1.0618 & -0.1728 & -0.1622 \\
\hline 17 & 1.0050 & 1.0662 & -0.1775 & -0.1696 \\
\hline 18 & 0.9906 & 1.0487 & -0.1893 & -0.1800 \\
\hline 19 & 0.9871 & 1.0477 & -0.1920 & -0.1825 \\
\hline 20 & 0.9926 & 1.0547 & -0.1888 & -0.1801 \\
\hline 21 & 0.9956 & 1.0684 & -0.1816 & -0.1773 \\
\hline 22 & 0.9965 & 1.0678 & -0.1816 & -0.1767 \\
\hline 23 & 0.9892 & 1.0476 & -0.1851 & -0.1763 \\
\hline 24 & 0.9819 & 1.0469 & -0.1877 & -0.1794 \\
\hline 25 & 0.9901 & 1.0527 & -0.1885 & -0.1794 \\
\hline 26 & 0.9651 & 1.0271 & -0.1917 & -0.1809 \\
\hline 27 & 1.0079 & 1.0694 & -0.1859 & -0.1773 \\
\hline 28 & 1.0121 & 1.0055 & -0.1195 & -0.1184 \\
\hline 29 & 0.9832 & 1.0448 & -0.2057 & -0.1942 \\
\hline 30 & 0.9696 & 1.0315 & -0.2208 & -0.2072 \\
\hline
\end{tabular}


Table 4. Reactive power flow with FACTS devices using PSO Approach.

\begin{tabular}{|c|c|c|c|}
\hline $\begin{array}{c}\text { Base Reactive } \\
\text { Load using } \\
\text { PSO }\end{array}$ & $\begin{array}{c}150 \% \text { Base } \\
\text { Reactive Load } \\
\text { using PSO } \\
\text { (p.u) }\end{array}$ & $\begin{array}{c}175 \% \text { Base } \\
\text { Reactive Load } \\
\text { using PSO } \\
\text { (p.u) }\end{array}$ & $\begin{array}{c}200 \% \text { Base } \\
\text { Reactive Load } \\
\text { using PSO } \\
\text { (p.u) }\end{array}$ \\
\hline 0.0133 & 0.0131 & 0.0129 & 0.0120 \\
0.0547 & 0.0524 & 0.0089 & 0.0641 \\
0.0146 & 0.0104 & -0.0443 & 0.0239 \\
0.0301 & 0.0218 & -0.0244 & 0.0273 \\
0.0384 & 0.0383 & 0.0385 & 0.0380 \\
0.0071 & 0.0099 & -0.0366 & 0.0258 \\
-0.0327 & -0.0035 & 0.0271 & 0.0076 \\
0.0806 & 0.1058 & 0.0739 & 0.1427 \\
0.0224 & 0.0525 & 0.1052 & 0.0714 \\
-0.2323 & -0.2438 & -0.0523 & -0.3106 \\
-0.3905 & -0.3893 & -0.4220 & -0.3623 \\
-0.1353 & -0.1340 & -0.1843 & -0.1116 \\
0.0634 & 0.0596 & 0.1285 & 0.0134 \\
0.0574 & 0.0620 & -0.1560 & 0.1365 \\
-0.2448 & -0.2429 & -0.2434 & -0.1913 \\
-0.0259 & -0.0305 & 0.0209 & -0.1573 \\
0.0110 & -0.0047 & -0.0231 & 0.0146 \\
0.0152 & -0.0627 & -0.1447 & -0.0034 \\
-0.0211 & -0.0094 & -0.1158 & 0.0007 \\
-0.0062 & -0.0298 & -0.0521 & -0.0186 \\
-0.0398 & -0.0371 & -0.1501 & -0.0360 \\
-0.0115 & 0.0173 & -0.0055 & 0.0165 \\
-0.0211 & 0.0032 & -0.0216 & -0.0021 \\
-0.0552 & -0.0479 & -0.0812 & -0.0702 \\
0.0651 & 0.0611 & 0.0975 & 0.0879 \\
0.0992 & 0.1259 & -0.0436 & 0.1544 \\
0.0990 & 0.0778 & -0.0729 & 0.0923 \\
0.0453 & 0.0388 & -0.0157 & 0.0495 \\
-0.0153 & 0.0102 & 0.1382 & 0.0323 \\
-0.0078 & 0.0253 & 0.0024 & 0.0298 \\
0.0290 & 0.0480 & 0.1212 & 0.0807 \\
-0.0241 & 0.0009 & -0.0258 & -0.0027 \\
-0.0169 & -0.0069 & 0.0234 & -0.0140 \\
0.0236 & 0.0353 & 0.0412 & 0.0472 \\
-0.0406 & -0.0422 & -0.0179 & -0.0612 \\
-0.1879 & -0.1738 & -0.1916 & -0.1419 \\
0.0164 & 0.0237 & 0.0272 & 0.0311 \\
0.0162 & 0.0233 & 0.0267 & 0.0305 \\
0.0060 & 0.0086 & 0.0099 & 0.0113 \\
0.0502 & 0.0559 & 0.0202 & 0.0756 \\
0.0096 & 0.0207 & 0.0360 & 0.0388 \\
\hline
\end{tabular}


Biplab Bhattacharyya, et al.

Table 5. Comparative analysis with and without FACTS devices with PSO based approach.

\begin{tabular}{|c|c|c|c|c|c|c|c|}
\hline $\begin{array}{c}\text { Reactive } \\
\text { Loading }\end{array}$ & $\begin{array}{c}\text { Active } \\
\text { Power } \\
\text { Loss } \\
\text { without } \\
\text { FACTS } \\
\text { (p.u) }\end{array}$ & $\begin{array}{c}\text { Operating } \\
\text { cost due to } \\
\text { the energy } \\
\text { loss } \\
\text { (in \$) } \\
\text { (A) }\end{array}$ & $\begin{array}{c}\text { Active } \\
\text { Power } \\
\text { Loss with } \\
\text { FACTS } \\
\text { using PSO } \\
\text { (p.u) }\end{array}$ & $\begin{array}{c}\text { Cost due to } \\
\text { energy loss } \\
\text { with FACTS }\end{array}$ & $\begin{array}{c}\text { Operating } \\
\text { Cost with } \\
\text { FACTS } \\
\text { devices } \\
\text { (in \$) } \\
\text { (B) }\end{array}$ & $\begin{array}{c}\text { Cost of } \\
\text { FACTS } \\
\text { devices }\end{array}$ & $\begin{array}{c}\text { Net } \\
\text { Saving }\end{array}$ \\
\hline $100 \%$ & 0.0711 & 3737016 & 0.0445 & 2338920 & $2.4052 \times 10^{6}$ & 66280 & $\begin{array}{c}\text { (in \$) } \\
\text { (A-B) }\end{array}$ \\
\hline $150 \%$ & 0.0742 & 3899952 & 0.0478 & 2512368 & $2.6080 \times 10^{6}$ & 95632 & 1291952 \\
\hline $175 \%$ & 0.0765 & 4020840 & 0.0497 & 2612232 & $2.7693 \times 10^{6}$ & 157068 & 1251540 \\
\hline $200 \%$ & 0.0795 & 4178520 & 0.0637 & $3.3481 \times 10^{6}$ & $3.4460 \times 10^{6}$ & 97900 & 732520 \\
\hline
\end{tabular}

Table 6. Comparative study of reactive power flow in line with PSO.

\begin{tabular}{|c|c|c|c|c|}
\hline Lines & $\begin{array}{c}\text { For base reactive } \\
\text { loading of } 150 \% \\
\text { (before) }\end{array}$ & $\begin{array}{c}\text { For base reactive } \\
\text { loading of } 150 \% \\
\text { (By the PSO based } \\
\text { approach) }\end{array}$ & $\begin{array}{c}\text { For reactive } \\
\text { loading of } \\
\text { 200\% (before) }\end{array}$ & $\begin{array}{c}\text { For base reactive } \\
\text { loading of 200\% } \\
\text { (By the PSO based } \\
\text { approach) }\end{array}$ \\
\hline 5 & 0.0387 & 0.0383 & 0.0384 & 0.0380 \\
\hline 25 & 0.0553 & 0.0611 & 0.0664 & 0.0879 \\
\hline 28 & 0.0650 & 0.0388 & 0.0883 & 0.0495 \\
\hline 41 & 0.0581 & 0.0207 & 0.0751 & 0.0388 \\
\hline 9 & 0.0884 & 0.0525 & 0.1032 & 0.0714 \\
\hline 18 & 0.0930 & -0.0627 & 0.1365 & -0.0034 \\
\hline 26 & 0.0735 & 0.1259 & 0.0860 & 0.1544 \\
\hline 27 & 0.1430 & 0.0778 & 0.1925 & 0.0923 \\
\hline
\end{tabular}


Table 7. Amount of facts devices and other reactive sources in the transmission network with PSO technique with different loading cases

\begin{tabular}{|c|c|c|c|c|}
\hline Loading & $\begin{array}{c}\text { SVC } \\
\text { amount } \\
\text { in p.u }\end{array}$ & $\begin{array}{c}\text { TCSC } \\
\text { amount in } \\
\text { lines in p.u }\end{array}$ & $\begin{array}{c}\text { Reactive } \\
\text { Generation } \\
\text { Qg in p.u }\end{array}$ & $\begin{array}{c}\text { Transformer } \\
\text { Tap Position }\end{array}$ \\
\hline & 0.0 & 0.1463 & 0.6 & 0.9 \\
$100 \%$ & 0.0 & 0.0419 & 0.0 & 0.9 \\
& 0.0 & 0.1049 & 0.0 & 0.9248 \\
& 0.0 & 0.1388 & 0.0 & 0.9 \\
\hline & 0.0869 & 0.1463 & 0.6 & 0.9 \\
$150 \%$ & 0.0 & 0.0419 & 0.0 & 0.9 \\
& 0.0 & 0.1049 & 0.0 & 0.9358 \\
& 0.1510 & 0.1388 & 0.2474 & 0.9 \\
\hline & 0.3202 & 0.1463 & 0.0672 & 0.9195 \\
$175 \%$ & 0.0063 & 0.0419 & 0.0183 & 0.9308 \\
& 0.2336 & 0.1049 & 0.4656 & 0.9673 \\
& 0.2018 & 0.1388 & 0.2370 & 0.9006 \\
\hline \multirow{5}{*}{$200 \%$} & 0.1457 & 0.1463 & 0.6 & 0.9 \\
& 0.0 & 0.0419 & 0.0 & 0.9 \\
& 0.0 & 0.1049 & 0.0 & 0.9483 \\
& 0.1089 & 0.1388 & 0.3168 & 0.9 \\
\hline
\end{tabular}

\section{Test Results \& Discussion}

The proposed approach for the placement of FACTS devices is applied on IEEE 30 Bus system. The power system is loaded (reactive loading is considered) and accordingly FACTS devices are placed at different locations of the power system. The power system is loaded up to the limit of $200 \%$ of base reactive load and the system performance is observed with and without FACTS devices. Table 1 shows the reactive power flow pattern without FACTS devices in different lines. Table 2 shows the locations of different FACTS devices in the transmission network. The magnitude and phase angle of the bus voltages with \& without FACTS devices for highest reactive loading i.e. for $200 \%$ is shown in Table 3. Phase angles are given in radian. Table 4 shows the reactive power flow pattern with FACTS devices in different lines using PSO based approach. A comparative analysis of active power loss and the operating cost of the system with and without FACTS devices using PSO technique are shown in Table 5. The change in reactive flow pattern in the lines where FACTS devices are connected for $150 \%$ and $200 \%$ base reactive loading is shown in Table 6 . Amount of FACTS devices, reactive generations of the generators and transformer tap positions in different cases of loading is shown in Table 7.

It is observed that SVC's are connected at the buses $21^{\text {st }}, 7^{\text {th }}, 17^{\text {th }} \& 15^{\text {th }}$ those are at the finishing ends of the lines $27^{\text {th }}, 26^{\text {th }}, 9^{\text {th }} \& 18^{\text {th }}$ respectively because these are the four lines carrying highest, second highest, third and fourth highest reactive power respectively, as seen from Table 1, without FACTS devices. After connecting SVC's at theses buses, voltage profile at these buses are improved, also reactive power flow reduces greatly in the lines $27^{\text {th }}, 26^{\text {th }}, 9^{\text {th }}$ $\& 18^{\text {th }}$ in each case of loading. TCSC's are placed in the lines $25^{\text {th }}, 41^{\text {st }}, 28^{\text {th }} \& 5^{\text {th }}$ as these are the next four highest reactive power carriers as seen from Table 1 .

From Table 5 we observe that transmission loss reduces significantly in all cases of loading with FACTS devices as compared to without such devices also we observe that operational cost is reduced significantly in all cases of loading with FACTS devices as well as significant 
economic gain is obtained even at a loading of $200 \%$ of base reactive loading. The economic gain obtained is much higher than the installation cost of FACTS devices in every cases of loading.

Here, energy cost is taken as $0.06 \$ / \mathrm{kWh}$.

\section{Conclusions}

In this approach, PSO (Particle Swarm Optimization) based optimal placement of FACTS devices in a transmission network is done for the increased load ability of the power system as well as to minimize the total operating cost. Cost of FACTS devices are very less compared to the benefits in terms of the system operating cost for each cases of loadings are clearly observed. Two different types of FACTS devices are considered. It is clearly evident from the results that effective placement of FACTS devices at proper locations by using suitable optimization technique can significantly improve system performance. Hence, this PSO based approach could be a new technique for the installation of FACTS devices in the transmission system.

\section{References}

[1] N. Hingorani, "Flexible AC Transmission," IEEE Spectrum, Vol. 30, No. 4, 40-45, 1993.

[2] M. Noroozian, G. Anderson, "Power Flow Control by use of controllable Series Components," IEEE Trans. Power Delivery, Vol. 8, No. 3, 1420-1429, 1993.

[3] M. Iravani, P. L. Dandeno, and D. Maratukulam, "Application of Static Phase Shifters in Power Systems,” IEEE Trans Power Delivery, Vol. 9, No. 3, 1600-1608, 1994.

[4] R. Nelson, J. Bian, and S. Williams, " Transmission Series Power Flow Control," IEEE Trans. Power Delivery, Vol. 10, No. 1, 504-510, 1995.

[5] H. Okamoto, A. Kurita and Y. Sekine, "A Method For Identification Of Effective Locations Of Variable Impedance Apparatus On Enhancement Of Steady-State Stability In Large Scale Power Systems," IEEE Trans. Power System, Vol. 10, No. 3, 1401-1407, 1995.

[6] T.T. Lie and W. Deng, "Optimal Flexible AC Transmission Systems (FACTS) devices allocation," Int. Journal of Electrical Power \& Energy Systems, Vol. 19, No. 2, 125-134, 1997.

[7] D.J. Gotham and G.T. Heydt, "Power Flow Control and Power Flow Studies for System with FACTS Devices," IEEE Trans. Power System, Vol. 13, No. 1, 60-65, 1998.

[8] Y. Xiao, Y. H. Song and Y. Z. Sun, "Power Flow Control Approach to Power Systems with Embedded FACTS Devices," IEEE Trans. Power System, Vol. 17, No. 4, 943-950, 2000.

[9] Y. Xiao, Y. H. Song, Liu Chen-Ching and Y. Z. Sun, "Available Transfer Capability Enhancement Using FACTS Devices," IEEE Trans. Power System, Vol. 18, No. 1, 305$312,2000$.

[10] F.D. Galiana and K. Almeida, "Assessment and Control Of The Impact Of FACTS Devices On Power System Performance," IEEE Transactions on Power Systems, Nov. 1996, Vol. 11, No. 4, 1931-1936, 2009.

[11] S. Gerbex, R. Cherkaoui, and A. J. Germond, "Optimal Location of Multi-Type FACTS Devices in a Power System by Means of Genetic Algorithms," IEEE Trans. Power System, Vol. 16, No. 3, 537-544, 2001.

[12] Q. Zaho and J. Jiang, "A TCSC damping controller design using robust control theory," Int. Journal of Electrical Power \& Energy System, Vol. 20, No. 1, 25-33, 1998.

[13] P.K. Dash, A.M. Sharaf and E.F. Hill, "An Adaptive Stabilizer For Thyristor Controlled Static Var Compensators For Power Systems," IEEE Trans. Power System, Vol. 4, No. 2, 403-410, 1989.

[14] M. O. Hassan, S. J. Cheng and Z. A. Zakaria, "Steady-State Modeling of SVC and TCSC for Power Flow Analysis", Int. MultiConference of Engineers and Computer Scientists 2009, Vol. II, IMECS 2009. 
[15] L.J. Cai, "Optimal Choice and Allocation of FACTS Devices in Deregulated Electricity Market Using Genetic Algorithms," IEEE, 0-7803-8718-X/04/2, 2004.

[16] B. Bhattacharyya, S.K. Goswami and R.C. Bansal, "Sensitivity Approach in Evolutionary Algorithms for Reactive Power Planning," Electric Power Components \& Systems, Vol. 37, No. 3, 287-299, 2009.

[17] Prasad Pandhy* N and M.A. Abdel Moamen, "Power flow control and solutions with multiple and multi-type FACTS devices," Electric Power Systems Research, 74, 341-351, 2005 .

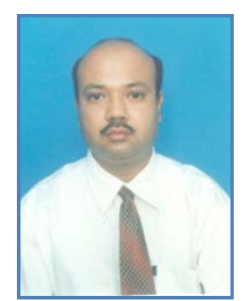

Biplab Bhattacharyya, is currently working as Associate Professor of Electrical Engineering in the Indian School of Mines University, Dhanbad, India. He has joined in the Electrical Engineering department as Assistant Professor in the year of 2007. Then he promoted to the post of Associate Professor on 2010. He had served department of Electrical Engineering of National Institute of Technology, Durgapur, India for six years as senior Lecturer. He was in the position of Lecturer in the Electrical Engineering department of BITS, Pilani, Rajasthan, India for nearly one year. He worked as Assistant Engineer (Electrical Test), in a reputed cable industry for nearly three years. He obtained B.sc (Hons) in Physics from Calcutta University, India in 1990. He obtained his BTech and M-Tech degree in the field of Electrical machines and Power system from Calcutta University in 1993 and 1995 respectively. He obtained his Phd degree in Engineering from the department of Electrical Engineering, Jadavpur University, India in 2006. He has published several technical papers in International/national Journals and conference proceedings. His research area mainly includes Evolutionary approaches, Power system optimization, Planning, Dispatch, FACTS devices.

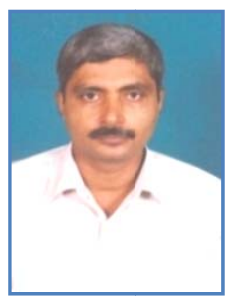

S.K. Goswami, currently is the professor of Electrical Engineering, Jadavpur University, India. $\mathrm{He}$ is in teaching profession for more than twenty five years. He has published number of technical papers in the international and national Journals. He has guided eleven Phd students till to date. His research area includes distribution planning, optimum operation of power system, AI application, deregulation, development of OPF based power system simulator etc.

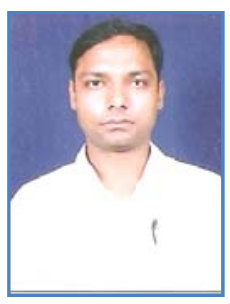

Vikash Kumar Gupta received B.E. degree Anna University, Chennai in 2009, and the M.Tech degree from B.I.T. Sindri, Dhnabad, Jharkhand in 2011. Currently, he is the Research Scholar in the Electrical Engineering Department, Indian School of Mines, Dhanbad, Jharkhand. His area of interest is Power System. 